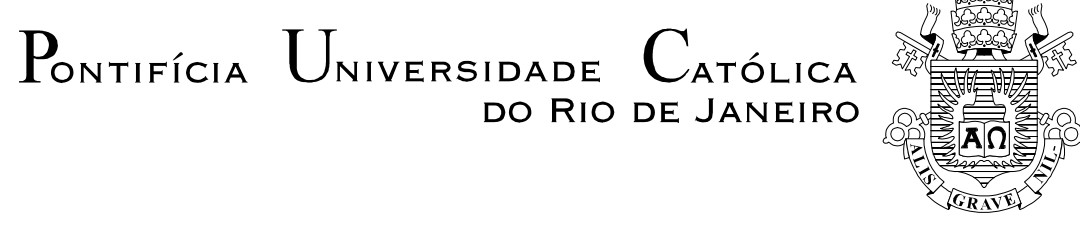

Carla Dodsworth Albano

\title{
Um Estudo de Caso da Abertura de Capital no Brasil: O IPO da América Latina Logística - ALL
}

\author{
Dissertação de Mestrado
}

\begin{abstract}
Dissertação apresentada como requisito parcial para obtenção do grau de Mestre pelo Programa de Pósgraduação em Administração de Empresas do Departamento de Administração da PUC-Rio.
\end{abstract}

Orientador: Prof. Luiz Felipe Jacques da Motta

Rio de Janeiro

Fevereiro de 2006 


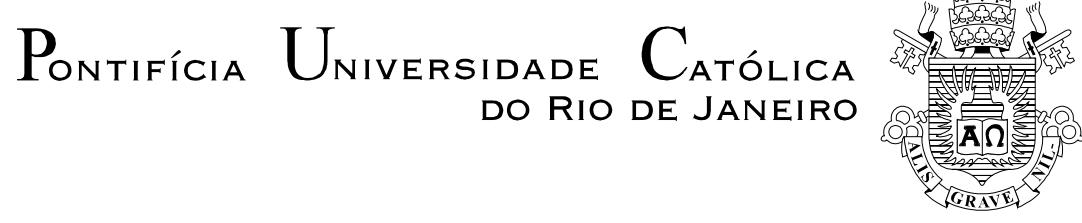

Carla Dodsworth Albano

\section{Um Estudo de Caso da Abertura de Capital no Brasil: O IPO da América Latina Logística - ALL}

Dissertação apresentada como requisito parcial para obtenção do título de Mestre pelo Programa de PósGraduação em Administração da PUC-Rio. Aprovada pela Comissão Examinadora abaixo assinada.

Prof. Luiz Felipe Jacques da Motta

Orientador

Departamento de Administração - PUC-Rio

Prof. Antonio Carlos Figueiredo Pinto Departamento de Administração - PUC-Rio

Prof. Marco Antonio Cunha de Oliveira Instituto Brasileiro de Mercado de Capitais - IBMEC

Rio de Janeiro, 22 de fevereiro de 2006 
Todos os direitos reservados. É proibida a reprodução total ou parcial do trabalho sem a autorização da Universidade, da autora e do orientador.

\section{Carla Dodsworth Albano}

Graduou-se em Economia pela PUC-Rio em 1999. MBA em Finanças Corporativas no IBMEC concluído em 2001. Atualmente é analista de negócios da Companhia Vale do Rio Doce atuando na área de M\&A da Diretoria de Finanças Corporativas, onde trabalha desde 2003. Iniciou sua carreira na Petros trabalhando com análise macroeconômica e avaliação de empresas e projetos.

Ficha Catalográfica

\section{Albano, Carla Dodsworth}

Um estudo de caso de abertura de capital no Brasil : o IPO da América Latina logística - ALL / Carla Dodsworth Albano ; orientador: Luiz Felipe Jacques da Motta. - Rio de Janeiro : PUC, Departamento de Administração, 2006.

$105 \mathrm{f.} ; 30 \mathrm{~cm}$

Dissertação (mestrado) - Pontifícia Universidade Católica do Rio de Janeiro, Departamento de Administração.

Inclui referências bibliográficas.

1. Administração - Teses. 2. Abertura de capital. 3. Emissão pública de ações. 4. Avaliação de investimentos. 5. Logística. 6. Brasil. I. Motta, Luiz Felipe Jacques da. II. Pontifícia Universidade Católica do Rio de Janeiro. Departamento de Administração. III. Título. 
Para minha mãe, Claudia, pela dedicação, formação de caráter, incentivo aos estudos e por ter me proporcionado esta oportunidade. 


\section{Agradecimentos}

Ao meu orientador, Luiz Felipe Jacques da Motta, pelo apoio e confiança em mim depositados e pela intelectualidade, experiência e simplicidade demonstradas no desenvolvimento desta dissertação.

Aos Professores Antonio Carlos Figueiredo Pinto e Marco Antonio de Oliveira, por terem participado da Comissão Examinadora e pelas valiosas sugestões..

Aos meus pais, Felipe e Claudia, pela educação e orientação que foram muito importantes para as minhas conquistas profissionais e acadêmicas.

A minha irmã, Paula, pelo companheirismo, amizade e paciência na revisão deste trabalho.

Ao meu marido, Bernardo Miller, pelo incentivo, apoio e compreensão.

Ao Diego pela amizade, carinho e apoio.

A todos os demais professores do Mestrado em Administração de Empresas da PUC-Rio, pelo esforço e sucesso na condução de suas disciplinas.

A todos os meus brilhantes colegas de turma que fizeram de nossa convivência um início de uma sólida amizade. 


\section{Resumo}

Albano, Carla Dodsworth; Motta, Luiz Felipe Jacques (Orientador). Um Estudo de Caso da Abertura de Capital no Brasil: O IPO da América Latina Logística - ALL. Rio de Janeiro, 2006. 105p. Dissertação de Mestrado - Departamento de Administração, Pontifícia Universidade Católica do Rio de Janeiro.

A abertura de capital (IPO) é um bom indicador da performance da economia. Mostra que as empresas estão tendo um bom resultado e que os investidores estão com mais confiança na economia. A atividade de IPO tem aumentado significativamente nos últimos anos mostrando uma maior confiança na economia, apesar de alguns mercados continuarem vulneráveis. Este trabalho tem por objetivo final apresentar as melhores práticas de avaliação de investimentos para empresas brasileiras de capital fechado e, portanto, oferecer às comunidades acadêmica e corporativa um serviço público - uma referência prática, através da avaliação da ALL - América Latina Logística. Busca-se, comparar o preço avaliado com o preço ofertado, verificando se o preço foi subavaliado e, ainda, comparar a performance da ação no primeiro dia de negociação com as empresas de outros setores.

\section{Palavras-chave}

Abertura de capital; emissão pública de ações; avaliação de investimentos; logística e Brasil. 


\section{Abstract}

Albano, Carla Dodsworth; Motta, Luiz Felipe Jacques (Advisor). A Case Study of The Initial Public Offering in Brazil: The IPO of América Latina Logística - ALL. Rio de Janeiro, 2006. 105p. MSc. Dissertation Departamento de Administração, Pontifícia Universidade Católica do Rio de Janeiro.

The initial public offering (IPO) is a good indicator of the economy situation. It reflects the strong performance of the companies and also the confidence of investors in the economy. The IPO activity has increased over the last years showing growth in confidence even when some markets are still vulnerable. The objective of this research is to present the practices in estimating the value of a private company, besides, it intends to provide a practical and "ready-to-use" tool to the academic and corporate communities, through the valuation of ALL - América Latina Logística. It aims as well to compare the stock price on its first traded day with the valuation pricing of ALL - América Latina Logística, to verify its fairness, and with other companies in different sectors.

\section{Keywords}

Initial public offering; equity valuation; investment analysis; logistics and Brazil. 


\section{Sumário}

1. O Problema da Pesquisa 13

1.1. Introdução 13

1.1.1. Motivação para abrir o capital? $\quad 14$

1.1.2. Motivação para não abrir o capital 16

1.2. Objetivos do Estudo $\quad 21$

1.3. Delimitação do Estudo $\quad 21$

1.4. Relevância do Estudo $\quad 22$

1.5. Organização do Trabalho 22

2. Referencial Teórico 24

2.1. Avaliação por Fluxo de Caixa Descontado - FCD 24

2.1.1. A Avaliação do Patrimônio Líquido 25

2.1.2. Avaliação da Empresa 26

2.1.3. Capital Cash Flow 26

2.1.4. Avaliação por Partes 27

2.2. Avaliação Relativa 28

2.2.1. Múltiplos de Lucro - Earnings 28

2.2.2. Índice de Valor de Mercado/ Valor Contábil (Book Value) - M/ B 29

2.2.3. Múltiplos de Vendas 29

2.3. Valor Presente Líquido - VPL 30

2.4. O Modelo CAPM 30

2.4.1. O Custo da Dívida, Kd 31

2.5. Custo Médio e Ponderado de Capital 31

3. Metodologia 33

3.1. Custo da Dívida

3.2. Estimando o Fluxo de Caixa 36

$\begin{array}{ll}\text { 3.3. Taxa de Crescimento } & 37\end{array}$

$\begin{array}{ll}\text { 3.4. Perpetuidade } & 37\end{array}$

3.5. Descontos de Liquidez 38

3.6. Cenário Macroeconômico 38

4. O Mercado de IPO 40

4.1. IPO de empresas de Logística 44

4.2. Abertura de Capital no Mercado Brasileiro 45

5. ALL - América Latina Logística $\quad 50$

$\begin{array}{ll}\text { 5.1. A Indústria } & 50\end{array}$

5.1.1. As Concessionárias $\quad 51$

5.2. Histórico da Empresa $\quad 57$

5.3. Estrutura Societária e Composição Acionária 59

5.4. Operação de Abertura de Capital 60

5.4.1. Motivação para abrir o capital $\quad 62$

5.4.2. Desempenho pós IPO 64

6. Resultados da Pesquisa 68 
6.1. Premissas da Avaliação $\quad 68$

6.1.1. CAPEX

6.1.2. Capital de Giro $\quad 75$

6.1.3. Recursos da Emissão $\quad 76$

6.2. Cálculo do WACC

6.3. Projeção por Fluxo de Caixa Descontado $\quad 79$

6.3.1. Análise de Sensibilidade $\quad 82$

6.4. Avaliação por Múltiplos $\quad 83$

6.5. Análise da Performance da ALL 89

7. Conclusão $\quad 92$

7.1. Sugestões para Próximos Estudos 95

8. Referências Bibliográficas 96

Anexo 1: Balanço Patrimonial Projetado para ALL 100

Anexo 2: DRE Projetado da ALL 101

Anexo 3: Projeção da Dívida 102

Anexo 4: Capital de Giro Projetado 103

Anexo 5: Premissas Macroeconômicas 104

Anexo 6: Metodologia de Avaliação dos Bancos 105 


\section{Lista de Tabelas}

Tabela 1: Ranking das Instituições Financeiras que participaram das emissões primárias (jan/05 - dez/05) 43

Tabela 2: Taxa de emissão (fee) por indústria (2003 - 2005) 44

Tabela 3: Ofertas primárias e secundárias de ações registradas na CVM 46

Tabela 4: Principais Acionistas da ALL em 31/12/03 60

Tabela 5: Operação de Abertura de capital da AL 60

Tabela 6: Distribuição secundária de ações da ALL 61

Tabela 7: Distribuição dos GDSs no exterior 62

Tabela 8: Composição Acionária da ALL pós Abertura de Capital 63

Tabela 9: Estrutura acionária da ALL em 30/09/05 67

Tabela 10: Potencial de aumentar a participação de mercado da ALL 69

Tabela 11: Volume Projetado da ALL (RTK bilhão) 69

Tabela 12: Preço Bruto Projetado da ALL (R\$) 70

Tabela 13: Evolução da Receita Bruta Projetada da ALL (R\$ MM) 70

Tabela 14: Evolução de Custos Projetada da ALL (abertura do CPV) 71

Tabela 15: Projeção do Número de vagões e locomotivas da ALL 2004 -

2013

Tabela 16: Evolução da dívida atrela da a US\$/ R\$ 76

Tabela 17: Cálculo do beta desalavancado da ALL $\quad 76$

Tabela 18: Tabela do cálculo do beta alavancado da ALL 77

Tabela 19: Tabela do cálculo do beta alavancado da ALL 78

Tabela 20: Fluxo de Caixa da Firma de 2004 - $2013 \quad 80$

Tabela 21: Cálculo do preço da ALL pelo Fluxo de Caixa da Firma 80

Tabela 22: Fluxo de Caixa da Firma de 2004 - 2013

Tabela 23: Cálculo do preço da ALL pelo Fluxo de Caixa do Acionista 81

Tabela 24: Análise de Sensibilidade do valor da ALL - Perpetuidade x

Taxa de Desconto 82

Tabela 25: Análise de Sensibilidade do valor da ALL - Risco País x Taxa de Desconto 83

Tabela 26: Análise dos Múltiplos das empresas norte americanas 87

Tabela 27: Preço da ALL por múltiplos de mercado 88

Tabela 28: Desempenho no Primeiro Dia de Empresas que abriram o Capital 90

Tabela 29: Comparação ALL: Executado x Projetado (2004) 91 


\section{Lista de Gráficos}

Gráfico 1 - Atividade Global de IPO 40

Gráfico 2: Volume de IPO (por mês) 41

Gráfico 3: Distribuição geográfica dos IPOs em 2005

Gráfico 4: Distribuição do IPOs de 2005 por setor 42

Gráfico 5: Distribuição geográfica dos IPOs de logística entre 1995 - 2005

(montante)

Gráfico 6: Distribuição geográfica dos IPOs de ferrovias entre 1995 - 2005 (montante)

Gráfico 7: Composição das Cargas transportadas (2000)

Gráfico 8: Evolução das ações preferenciais da ALL. $\quad 65$

Gráfico 9: Evolução do preço das UNITS da ALL 66

Gráfico 9a: Ferrovias Universo Brasileiro (incidentes / milhão de km) 72

Gráfico 10: Ferrovias Universo Americano (acidentes / milhão de km) 72

Gráfico 11: Produtividade dos Funcionários (TKU / funcionário) 73

Gráfico 12: Produtividade dos Locomotivas (TKU / Kgf) 73

Gráfico 13: Projeção do CAPEX (RS MM)

Gráfico 14: Projeção do Capital de Giro da ALL (em dias) 75

Gráfico 15: Cálculo do WACC $\quad 79$

Gráfico 16: Participação de Mercado das Ferrovias Classe I Norte

Americanas

Gráfico 17: Avaliação do preço para as ações da ALL (em R\$) 89

Gráfico 18: Evolução da Dívida Líquida / EBITDA da ALL (1997 - 2004) 94 


\section{Lista de Figuras}

Figura 1: Mapa Ferroviário Brasileiro 52

Figura 2: Mapa Ferroviário da América Latina Logística 57

Figura 3: Estrutura Acionária da ALL 59

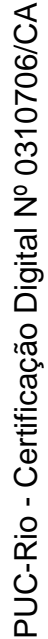

